\title{
Clinical and Molecular Epidemiology of Extended- Spectrum Beta-Lactamase-Producing Escherichia Coli Infections in Metro Detroit: Early Dominance of the ST-131 Clone
}

\author{
John P. Mills (D) - Keith S. Kaye - Richard Evans · Elizabeth Salzman • \\ Jason Pogue · Kayoko Hayakawa • Dror Marchaim • Pansy Awasthy • \\ Madiha Salim • Emily T. Martin
}

Received: May 27, 2020 / Published online: July 18, 2020

(C) The Author(s) 2020

\section{ABSTRACT}

Introduction: Extended-spectrum beta-lactamase (ESBL)-producing Escherichia coli infections have become endemic worldwide. We aimed to describe the molecular and clinical epidemiology of ESBL-producing E. coli infections during a period of rising global prevalence.

Digital Features To view digital features for this article go to https://doi.org/10.6084/m9.figshare.12582083.

Electronic supplementary material The online version of this article (https://doi.org/10.1007/s40121020-00321-6) contains supplementary material, which is available to authorized users.

J. P. Mills $(\bowtie) \cdot$ K. S. Kaye

Department of Internal Medicine, Division of Infectious Diseases, University of Michigan Health System, Ann Arbor, MI, USA

e-mail:millsjo@umich.edu

K. S. Kaye - R. Evans · E. Salzman - E. T. Martin Department of Epidemiology, University of Michigan School of Public Health, Ann Arbor, MI, USA

J. Pogue

Department of Pharmacy, University of Michigan, Ann Arbor, MI, USA

\section{K. Hayakawa}

Department of Infectious Diseases, Disease Control and Prevention Center, National Center for Global Health and Medicine, Tokyo, Japan
Methods: Three hundred sixty-nine consecutive ESBL-producing E. coli infections in Detroit from 2010-2011 were analyzed. Sequence typing (ST) and $\mathrm{CH}$ typing were performed. Clinical characteristics and outcomes were compared between patients infected with ST131 and nonST131 isolates.

Results: Ninety-six percent of isolates were ST 131 , and $78.6 \%$ of ST 131 isolates produced

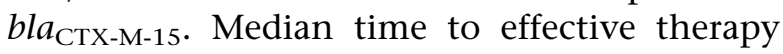
was $48 \mathrm{~h}$ vs. $35 \mathrm{~h}(P=0.38)$ in the ST131 vs. non-ST131 groups. Ninety-day mortality rates ( $8 \%$ vs. $8 \%, P=1.0$ ) were similar between the two groups.

Conclusion: bla $a_{\mathrm{CTX}-\mathrm{M}-15}$ ST131 E. coli predominated in Detroit during an early period of global ST131 dissemination. Patients with ST131 E. coli

\section{Marchaim}

Assaf Harofeh Medical Center, Zerifin and Sackler School of Medicine, Tel-Aviv University, Tel Aviv, Israel

\section{P. Awasthy}

Department of Pharmacy Services, Sinai-Grace Hospital, Detroit Medical Center, Wayne State University School of Medicine, Detroit, MI, USA

\section{Salim}

Department of Medicine, Detroit Medical Center, Wayne State University, Detroit, MI, USA 
infections had similar clinical outcomes to those with non-ST131 E. coli infections.

Keywords: Escherichia coli; Extended spectrum beta-lactamase; Sequence typing

\section{Key Summary Points}

Extended-spectrum beta-lactamase (ESBL)producing $E$. coli are the most common cause of community-acquired multidrugresistant gram-negative bacterial infections.

Dissemination of ESBL-producing E. coli has been driven by several factors, most notably the expansion of sequence type (ST) 131.

This study sought to determine the sequence type (ST) of 369 consecutive clinical isolates of ESBL-producing $E$. coli at a Detroit hospital and compare clinical features of those with ST131 versus nonST131.

96\% of ESBL-producing E. coli isolates were ST131, suggesting rapid clonal spread of ST 131 E. coli at an early period of global dissemination.

Clinical characteristics of patients with infections due to ST131 were similar to those with infections due to non-ST131 isolates, though this analysis was limited by the small number of non-ST131 isolates.

\section{INTRODUCTION}

The number of infections due to multidrug-resistant Escherichia coli has increased dramatically in the past 20 years. The emergence of community-acquired infections due to extended-spectrum beta-lactamase (ESBL)-producing E. coli began in the late 1990s and has since spread worldwide. Large-scale epidemiologic studies suggest this increase has been largely driven by global expansion of the multilocus sequence type (ST) 131 clone, which is associated with carriage of plasmid-mediated CTX-M beta-lactamase [1-3].

The expansion of the accessary genome, including antimicrobial resistance and virulence genes, along with a wide host range, has contributed to the ST131 H3O subclone predomination in recent years. The presence of fluoroquinolone resistance mutations in gyrA and parC, as well as the ESBL and $b l a_{\mathrm{CTX}}$ in ST131, has been associated with delayed time to appropriate antibiotic therapy and prolonged hospital stays [4-6]. Whether ST131 itself is a marker for increased virulence in E. coli infections, independent of antibiotic susceptibility, remains unclear $[7,8]$.

This study aimed to determine the clinical and molecular epidemiology as well as clinical outcomes of a large cohort of patients with ESBL-producing E. coli infections in the context of $E$. coli sequence type. We specifically sought to better characterize the ST distribution in Detroit, MI, during an early phase of the documented ST131 global spread to inform knowledge on the rate of spread in North America and to demonstrate how molecular typing data can provide valuable public health information regarding the epidemiology of resistance dissemination.

\section{METHODS}

A retrospective analysis was performed with participant data and bacterial isolates obtained as part of a previously conducted study of patients with ESBL-producing $E$. coli infections admitted from February 2010 through July 2011 at any of eight Detroit Medical Center hospitals [9]. Approval was obtained from the Wayne State University Institutional Review Board.

\section{Determination of E-Coli Sequence Type and Resistance Genes}

ST131 and 2-locus CH-typing were determined using multiplex PCR (CITE) and sequencing of the fum $C$ and $f i m H$ genes $[10,11]$. The presence 
of ESBL genes $b l a_{\mathrm{CTX}-\mathrm{M}-14}, b l a_{\mathrm{CTX}-\mathrm{M}-15}, b l a_{\mathrm{SHV}}$, and $b l a_{\text {TEM }}$ was determined by PCR as part of earlier analyses of these isolates. The antimicrobial susceptibility profile of these isolates was also previously described in the same study [9].

\section{Data Collection}

Medical records were reviewed to abstract patient demographics, medical history, and variables relevant to infection severity and clinical course. All instances of potential treatment failure or adverse events were reviewed by a study clinician (M.S.). Effective antibiotic therapy was defined as use of an agent with in vitro activity against the pathogen (according to susceptibility testing performed on Microscan). Timely receipt of effective therapy was defined as effective therapy provided within $48 \mathrm{~h}$ of admission.

\section{Statistical Analysis}

Variables were compared between ST131 and non-ST131 groups using $\chi^{2}$ tests for categorical variables and $t$ test for continuous measures. Parametric methods (Fisher's exact and Wilcoxon rank sum tests) were used in cases of small numbers. Analyses of treatment outcomes were performed using logistic regression, controlling for timely receipt of effective therapy and patient factors potentially associated with both clonal type and outcome (effective therapy within $48 \mathrm{~h}$, age, sex, Charlson comorbidity score).

\section{RESULTS}

The cohort included 369 individuals with ESBLproducing $E$. coli infections and has been described in detail elsewhere [9]. The study population had a mean age of 68 years (SD 17.5); $42 \%$ were male and $66 \%$ African American $(n=245)$ (Table 1). More than half of the subjects resided in nursing facilities and/or had been recently hospitalized; $77.3 \%$ of the pathogens were recovered within the first $48 \mathrm{~h}$ of hospitalization. The majority of isolates were cultured from the urine $(76 \% ; n=281)$ followed by blood $(7 \% ; n=27)$, sputum $(6 \% ; n=24)$, and wounds $(4 \%, n=14)$.

A total of 351 ST131 isolates were identified (96\%). Among the 313 ST131 isolates tested by $\mathrm{CH}$ typing, H30 was the most common subclone ( $n=249 ; 80 \%$ ) (Table 2$)$. While the resistance element CTX-M-15 was identified more often among ST131 isolates, it was also found among non-ST131 isolates. CTX-M-14 was present more frequently in non-ST131 isolates (Table 1). Multiple ESBL types were identified in 137 ST131 isolates.

Patient characteristics were largely similar between ST131 and non-ST131 groups (Table 1). Median time to effective therapy was $48 \mathrm{~h}$ in the ST131 group and $35 \mathrm{~h}$ in the non-ST131 group $(P=0.38)$. A total of 68 individuals were readmitted within 30 days of discharge (18\%), and 16 of these admissions were infection related. Twenty individuals died during their hospital admission (5.8\%) with five deaths determined to be due to infection. Forty-three percent of patients $(n=96)$ were discharged to a long-term care facility. In unadjusted analyses, outcomes were largely similar between the ST131 and non-ST131 groups [Supplemental table]. In a logistic regression, ST131 was not associated with worse outcomes compared to non-ST131 ESBL-producing E. coli infections, controlling for effective therapy within $48 \mathrm{~h}$, age, sex, and Charlson comorbidity score. Patients with ST131 infection had lower odds of readmission following discharge, at both 30-day [AOR 0.43 $(95 \%$ CI $0.19,0.99)$ and 60-day (AOR 0.43 (95\% CI 0.18, 0.95] time points [Supplemental table].

\section{DISCUSSION}

An unexpected finding in our study population was the extremely high prevalence of ST131 in our sample of sequentially collected ESBL-producing E. coli isolates (96\%) during an early point in the rise of worldwide ESBL prevalence, which is much higher than rates reported in other studies. Data from the same time period (2010-2011) from France found that ST131 comprised $20 \%$ of ESBL-producing E. coli isolates, and data from Chicago found that ST131 
Table 1 Demographic, clinical, and molecular characteristics

\begin{tabular}{|c|c|c|c|}
\hline $\begin{array}{l}\text { Patient characteristics } \\
\text { Categorical }\end{array}$ & $\begin{array}{l}\text { Non-ST131 }(N=15) \\
\text { No./total no. }(\%)\end{array}$ & $\begin{array}{l}\text { ST131 }(N=351) \\
\text { No./total no. }(\%)\end{array}$ & $P$ value* \\
\hline Age $\geq 65$ years & $8 / 15(53.3)$ & $216 / 350(61.7)$ & 0.49 \\
\hline Male & $5 / 15(33.3)$ & $146 / 351(41.6)$ & 0.57 \\
\hline Obesity & $5 / 15(33.3)$ & $118 / 350(33.7)$ & 0.95 \\
\hline Residence (LTCF/nursing home) & $7 / 15(46.7)$ & $180 / 346(52.0)$ & 0.69 \\
\hline Recent hospitalization & $6 / 14(42.9)$ & $197 / 340(57.9)$ & 0.27 \\
\hline Continuous & Median (IQR) & Median (IQR) & \\
\hline Age & $67(33,81)$ & $69(57,81)$ & 0.05 \\
\hline BMI & $24(21,33)$ & $26(23,32)$ & 0.83 \\
\hline LOS total, days & $7(1,9)$ & $7(4,13)$ & 0.62 \\
\hline \multicolumn{4}{|c|}{ History of present illness/past medical history } \\
\hline Categorical & No./total no. (\%) & No./total no. (\%) & \\
\hline History of nursing care & $3 / 12(25.0)$ & $69 / 232(29.7)$ & 0.84 \\
\hline History of urinary tract infection & $5 / 12(41.7)$ & $119 / 311(38.3)$ & 0.77 \\
\hline Obstructive urinary diseases & $2 / 12(16.7)$ & $34 / 332(10.2)$ & 0.30 \\
\hline Urolithiasis & $0 / 12(0)$ & $15 / 331(4.50)$ & 0.82 \\
\hline Hemodialysis & $1 / 12(8.30)$ & $21 / 333(6.30)$ & 0.41 \\
\hline Past urologic procedure & $0 / 12(0)$ & $24 / 334(7.20)$ & 0.86 \\
\hline Past invasive procedure & $1 / 12(8.30)$ & $76 / 338(22.5)$ & 0.40 \\
\hline Past surgery & $3 / 13(23.1)$ & $78 / 337(23.1)$ & 0.86 \\
\hline Hemiplegia & $0 / 12(0)$ & $49 / 333(14.7)$ & 0.74 \\
\hline Diabetes mellitus & $4 / 13(30.8)$ & $144 / 349(42.4)$ & 0.46 \\
\hline Continuous & Median (IQR) & Median (IQR) & \\
\hline Weighted Charlson score & $1.00(1.00,3.75)$ & $3.00(2.00,5.00)$ & 0.08 \\
\hline Combined comorbidity score & $5.00(1.00,7.00)$ & $6.00(4.00,8.00)$ & 0.08 \\
\hline Resistance element & No./total no. (\%) & No./total no. (\%) & \\
\hline TEM & $8(53.3)$ & $156(44.4)$ & 0.50 \\
\hline SHV & $2(13.3)$ & $31(8.8)$ & 0.36 \\
\hline CTX-M (any) & $9(60.0)$ & $301(85.8)$ & 0.01 \\
\hline CTX-M-14 & $5(33.3)$ & $46(13.1)$ & 0.02 \\
\hline
\end{tabular}


Table 1 continued

\begin{tabular}{llll}
\hline $\begin{array}{l}\text { Patient characteristics } \\
\text { Categorical }\end{array}$ & $\begin{array}{l}\text { Non-ST131 }(\boldsymbol{N}=15) \\
\text { No./total no. }(\%)\end{array}$ & $\begin{array}{l}\text { ST131 }(\boldsymbol{N}=351) \\
\text { No./total no. (\%) }\end{array}$ & $\boldsymbol{P}$ value* $^{*}$ \\
\hline CTX-M-15 & $4(26.7)$ & $276(78.6)$ & $<0.01$ \\
\hline
\end{tabular}

LTCF long-term care facility, BMI body mass index, LOS length of stay, UTI urinary tract infection, IQR interquartile range

*Probability values derived from univariate bias-corrected logistic regression

comprised $49 \%$ of isolates in Chicago $[12,13]$. In the current study, $80 \%$ of ST131 samples with fimH sequencing performed had an $\mathrm{H}$ allele type of H30, the ST131 subclone that has been most closely associated with fluoroquinolone resistance. This high proportion of ST131/H30 isolates is consistent with other studies from Detroit, which have reported high rates of resistant organisms and newly emergent strains [14-16]. Data utilizing whole-genome sequencing of almost 2000 clinical E. coli isolates from the US and Germany during the 2010-2011 period demonstrated that nearly all CTX-M ESBL-producing E. coli infections were due to the H30-Rx ST131 subclone, which was associated with higher rates of sepsis [17]. The current data echo this finding of rapid clonal expansion.

We found no increase in the severity of infection or increased occurrence of adverse patient outcomes of patients with ST131 infections compared to those with non-ST131 infections. In fact, patients with ST131 infection were readmitted less often following discharge in both adjusted and unadjusted models, though numbers of non-ST131 infections were small. The lack of differences observed in clinical outcomes between ST131 and non-ST131 populations were possibly due to the small sample size of non-ST131isolates, limiting statistical power [18]. Additionally, our patient population had higher rates of chronic illness (in both the ST131 and non-ST131 groups) than many prior studies of ESBL-producing E. coli infections, with $49 \%$ admitted from nursing home or long-term care facility residences, and the average Charlson score was 3.5.

Patients infected with ESBL-producing E. coli were generally elderly with multiple comorbidities and significant prior healthcare exposure, including prior LTCF stays and acute care hospitalizations. The current results suggest that elderly patients in skilled nursing facilities or with other recent healthcare exposures should be considered at increased risk for infection due to ST131 E. coli. Rates of 30-day readmission, and particularly readmission due to infection, were high. Given that the minority of readmissions were due to infection, the overall readmission rate may be driven by the high level of chronic disease in this population.

These data are limited by the narrowly defined patient group, i.e., hospitalized patients infected with ESBL-producing E. coli. However, this allowed for the comparison of patient outcomes within a very specifically characterized phenotypic group, lessening the potential for unmeasured bias between ST131 and nonST131 groups. Additionally, our use of a multiplex PCR-based assay has potential to produce false-negative results and may miss non-025b subtypes of ST131. All negative results were tested in duplicate, and additional sequencing of the H30 allele in a selection of isolates was performed to reduce the likelihood of falsenegative results. While these data are several years old, we believe that the lessons learned from this study are important and applicable to the current study of E. coli and other resistant bacteria.

This study identified ESBL production among several non-ST131 E. coli strain types. Therefore, the use of ST131 typing alone should not be used to definitively determine resistance patterns. Susceptibility and molecular resistance gene-based assays remain the most effective diagnostic tests in determining optimal antimicrobial therapy for extraintestinal E. coli infections. However, strain typing can be useful in helping to understand important 
Table 2 fum $C /$ fim $H(\mathrm{CH})$ alleles of ESBL-Producing E. coli Isolates

\begin{tabular}{|c|c|c|}
\hline CH type & Non-ST131 & ST131 \\
\hline $04-02$ & 1 & 0 \\
\hline $04-142$ & 0 & 1 \\
\hline $04-27$ & 0 & 1 \\
\hline $04-29$ & 0 & 1 \\
\hline $04-30$ & 0 & 2 \\
\hline $04-305$ & 0 & 1 \\
\hline $04-58$ & 0 & 1 \\
\hline $103-30$ & 0 & 1 \\
\hline $103-74$ & 0 & 1 \\
\hline $106-30$ & 0 & 1 \\
\hline $106-54$ & 1 & 0 \\
\hline $11-54$ & 0 & 1 \\
\hline $13-06$ & 0 & 1 \\
\hline $13-30$ & 0 & 1 \\
\hline $14-02$ & 0 & 2 \\
\hline $14-30$ & 0 & 1 \\
\hline $14-54$ & 0 & 1 \\
\hline $187-95$ & 0 & 1 \\
\hline $23-30$ & 0 & 1 \\
\hline $26-05$ & 0 & 1 \\
\hline $26-30$ & 0 & 1 \\
\hline $26-65$ & 1 & 0 \\
\hline $35-27$ & 0 & 2 \\
\hline $37-27$ & 0 & 1 \\
\hline $37-29$ & 0 & 2 \\
\hline $38-05$ & 1 & 0 \\
\hline $38-26$ & 1 & 0 \\
\hline $38-41$ & 0 & 2 \\
\hline $40-142$ & 0 & 1 \\
\hline $40-24$ & 1 & 0 \\
\hline $40-27$ & 0 & 4 \\
\hline $40-30$ & 0 & 122 \\
\hline
\end{tabular}

Table 2 continued

\begin{tabular}{llc}
\hline CH type & Non-ST131 & ST131 \\
\hline $45-97$ & 1 & 0 \\
$88-145$ & 1 & 0 \\
Unknown $^{\mathrm{a}}$ & 7 & 196 \\
\hline
\end{tabular}

${ }^{a}$ Of 162 with unknown fumC allele, 119 (73\%) were fim $H$ type 30. Of 11 with unknown fim $H$ allele, fumC types were $11(n=6), 26(n=2), 13(n=1), 19(n=1)$, $88(n=1)$

epidemiologic characteristics of pathogen and resistance spread.

\section{CONCLUSION}

Molecular typing of ESBL-producing E. coli will continue to help to define population-based patterns of $E$. coli spread. In this study, sequence typing revealed that ST131 dissemination in specific regions of North America likely occurred more rapidly than previously estimated. Outcomes among those patients infected with ST131 were similar to those infected with nonST131 E. coli isolates. These findings underscore the importance of molecular typing to identify early changes in the prevalence of strains with associated antimicrobial resistance genes, regardless of the specific pathogen. Further refinements in the study of $E$. coli population genetics, including clade typing and accessory genome sequencing, will be valuable public health tools to provide insights into the patterns and epidemiology of resistance transmission.

\section{ACKNOWLEDGEMENTS}

Funding. This study was supported in part by an investigator-initiated grant from Merck and Co., Inc., Kenilworth, NJ, to K.S.K. and E.T.M. K.S.K. was funded by the National Institute of Allergy and Infectious Diseases (DMID protocol no. 10-0065 and R01-AI119446-01). 
No funding or sponsorship was received for the publication of this article.

Authorship. All named authors meet the International Committee of Medical Journal Editors (ICMJE) criteria for authorship for this article, take responsibility for the integrity of the work as a whole, and have given their approval for this version to be published.

Disclosures. Keith S. Kaye has served as a consultant for Merck \& Co., Melinta Therapeutics, and Nabriva. John P Mills, Richard Evans, Elizabeth Salzman, Jason Pogue, Kayoko Hayakawa, Dror Marchaim, Pansy Awasthy, Madiha Salim, and Emily Martin have nothing to declare.

Compliance with Ethics Guidelines. Approval was obtained from the Wayne State University Institutional Review Board.

Data Availability. All data generated or analyzed during this study are included in this published article as supplementary information files.

Open Access. This article is licensed under a Creative Commons Attribution-NonCommercial 4.0 International License, which permits any non-commercial use, sharing, adaptation, distribution and reproduction in any medium or format, as long as you give appropriate credit to the original author(s) and the source, provide a link to the Creative Commons licence, and indicate if changes were made. The images or other third party material in this article are included in the article's Creative Commons licence, unless indicated otherwise in a credit line to the material. If material is not included in the article's Creative Commons licence and your intended use is not permitted by statutory regulation or exceeds the permitted use, you will need to obtain permission directly from the copyright holder. To view a copy of this licence, visit http:// creativecommons.org/licenses/by-nc/4.0/.

\section{REFERENCES}

1. Nicolas-Chanoine $\mathrm{MH}$, Blanco J, Leflon-Guibout V, Demarty R, Alonso MP, Canica MM, et al. Intercontinental emergence of Escherichia coli clone O25: H4-ST131 producing CTX-M-15. J Antimicrob Chemother. 2008;61(2):273-81.

2. Johnson JR, Porter S, Thuras P, Castanheira M. Epidemic emergence in the United States of Escherichia coli Sequence Type 131-H30 (ST131H30), 2000 to 2009. Antimicrob Agents Chemother. 2017;61(8):e00732-17. https://doi.org/10.1128/ AAC.00732-17.

3. Manges AR, Geum HM, Guo A, Edens TJ, Fibke CD, Pitout JDD. Global extraintestinal pathogenic Escherichia coli (ExPEC) Lineages. Clin Microbiol Rev. 2019;32(3):e00135-18. https://doi.org/10. 1128/CMR.00135-18.

4. Johnson JR, Tchesnokova V, Johnston B, Clabots C, Roberts PL, Billig M, et al. Abrupt emergence of a single dominant multidrug-resistant strain of Escherichia coli. J Infect Dis. 2013;207(6):919-28.

5. Doi Y, Park YS, Rivera JI, Adams-Haduch JM, Hingwe A, Sordillo EM, et al. Community-associated extended-spectrum beta-lactamase-producing Escherichia coli infection in the United States. Clin Infect Dis. 2013;56(5):641-8.

6. Peirano G, Pitout JDD. Extended-spectrum $\beta$-lactamase-producing Enterobacteriaceae: update on molecular epidemiology and treatment options. Drugs. 2019;79(14):1529-41.

7. Lautenbach E. Editorial commentary: flying under the radar: the stealth pandemic of Escherichia coli sequence type 131. Clin Infect Dis. 2013;57(9): 1266-9.

8. Mathers AJ, Peirano G, Pitout JD. The role of epidemic resistance plasmids and international highrisk clones in the spread of multidrug-resistant Enterobacteriaceae. Clin Microbiol Rev. 2015;28(3): 565-91.

9. Hayakawa K, Gattu S, Marchaim D, Bhargava A, Palla M, Alshabani K, et al. Epidemiology and risk factors for isolation of Escherichia coli producing CTX-M-type extended-spectrum beta-lactamase in a large U.S. Medical Center. Antimicrob Agents Chemother. 2013;57(8):4010-8.

10. Tartof SY, Solberg OD, Riley LW. Genotypic analyses of uropathogenic Escherichia coli based on fimH single nucleotide polymorphisms (SNPs). J Med Microbiol. 2007;56(Pt 10):1363-9. 
11. Clermont O, Dhanji H, Upton M, Gibreel T, Fox A, Boyd D, et al. Rapid detection of the O25b-ST131 clone of Escherichia coli encompassing the CTX-M15-producing strains. J Antimicrob Chemother. 2009;64(2):274-7.

12. Banerjee R, Robicsek A, Kuskowski MA, Porter S, Johnston BD, Sokurenko E, et al. Molecular epidemiology of Escherichia coli sequence type 131 and Its H30 and H30-Rx subclones among extendedspectrum-beta-lactamase-positive and -negative $E$. coli clinical isolates from the Chicago Region, 2007 to 2010. Antimicrob Agents Chemother. 2013;57(12):6385-8.

13. Sauget M, Cholley $P$, Vannier A, Thouverez M, Nicolas-Chanoine MH, Hocquet D, et al. Trends of extended-spectrum beta-lactamase-producing Escherichia coli sequence type 131 and its H30 subclone in a French hospital over a 15-year period. Int J Antimicrob Agents. 2016;48(6):744-7.

14. Dhar S, Martin ET, Lephart PR, McRoberts JP, Chopra T, Burger TT, et al. Risk factors and outcomes for carbapenem-resistant Klebsiella pneumoniae isolation, stratified by its multilocus sequence typing: ST258 versus non-ST258. Open Forum Infect Dis. 2016;3(1):ofv213.

15. Lazarovitch T, Amity K, Coyle JR, Ackerman B, TalJasper R, Ofer-Friedman H, et al. The complex epidemiology of carbapenem-resistant enterobacter infections: a multicenter descriptive analysis. Infect Control Hosp Epidemiol. 2015;36(11):1283-91.

16. Mody L, Gibson KE, Horcher A, Prenovost K, McNamara SE, Foxman B, et al. Prevalence of and risk factors for multidrug-resistant Acinetobacter baumannii colonization among high-risk nursing home residents. Infect Control Hosp Epidemiol. 2015;36(10):1155-62.

17. Price LB, Johnson JR, Aziz M, Clabots C, Johnston B, Tchesnokova $\mathrm{V}$, et al. The epidemic of extendedspectrum-beta-lactamase-producing Escherichia coli ST131 is driven by a single highly pathogenic subclone, H30-Rx. mBio. 2013;4(6):e00377-13.

18. Can F, Azap OK, Seref C, Ispir P, Arslan H, Ergonul O. Emerging Escherichia coli $\mathrm{O} 25 \mathrm{~b} / \mathrm{ST} 131$ clone predicts treatment failure in urinary tract infections. Clin Infect Dis. 2015;60(4):523-7. 